\title{
The Aerobiology of Apple Scab
}

Apple scab, caused by the fungus Venturia inaequalis (Cooke) G. Wint., is a disease of the fruit and leaves of apple trees. On fruit, it produces scablike lesions (Fig. 1) that can cause the fruit to deform and crack. Economic losses can be compounded by secondary rotting pathogens that enter these wounds and further destroy the apples. Scab is important in areas of rain-fed agriculture throughout the world and must be controlled to produce marketable fruit on susceptible varieties (38).

$V$. inaequalis survives the winter primarily in diseased apple leaves on the ground. Pseudothecia and ascospores develop in these leaves (Fig. 2) as spring approaches. In the northeastern United States, the first ascospores mature and are released into the air at a time roughly corresponding to the emergence of the first green tissues on McIntosh apple trees. Ascospores are carried by the wind to the developing fruit and shoot buds, where they cause primary infections that can lead to lesions and production of conidia. Disease increases in an orchard by repeated cycles of infection by conidia. Established apple scab colonies return to the ground on fallen, infected apple leaves, where the fungus survives the winter and develops ascospores ready to begin the cycle anew the following spring.

Chemical control of apple scab is concentrated on primary infections caused by ascospores (Fig. 3). Strategies in current use are based on years of study of the biology and epidemiology of apple scab $(1,29,30,35,36,39,40,44,45,53)$. Improved strategies for reducing fungicide use are being developed based, in part, on a better understanding of the concurrent temporal development of ascospores, host foliage and fruit area, the susceptibility of host tissue to infection, and the aerial dispersal of ascospores (11,16,17,28,31-33,37,4143). The success of strategies for reduced

Dr. Aylor's address is: Plant Pathology and Ecology, The Connecticut Agricultural Experiment Station, P.O. Box 1106, New Haven, CT 06504; Email: donaylor@caes.state.ct.us

Publication no. D-1998-0529-01F

(C) 1998 The American Phytopathological Society fungicide use generally requires that inoculum levels be low in and near a managed orchard. What level of inoculum is low enough to ensure success? This question can be addressed using an aerobiological model of the apple scab fungus.

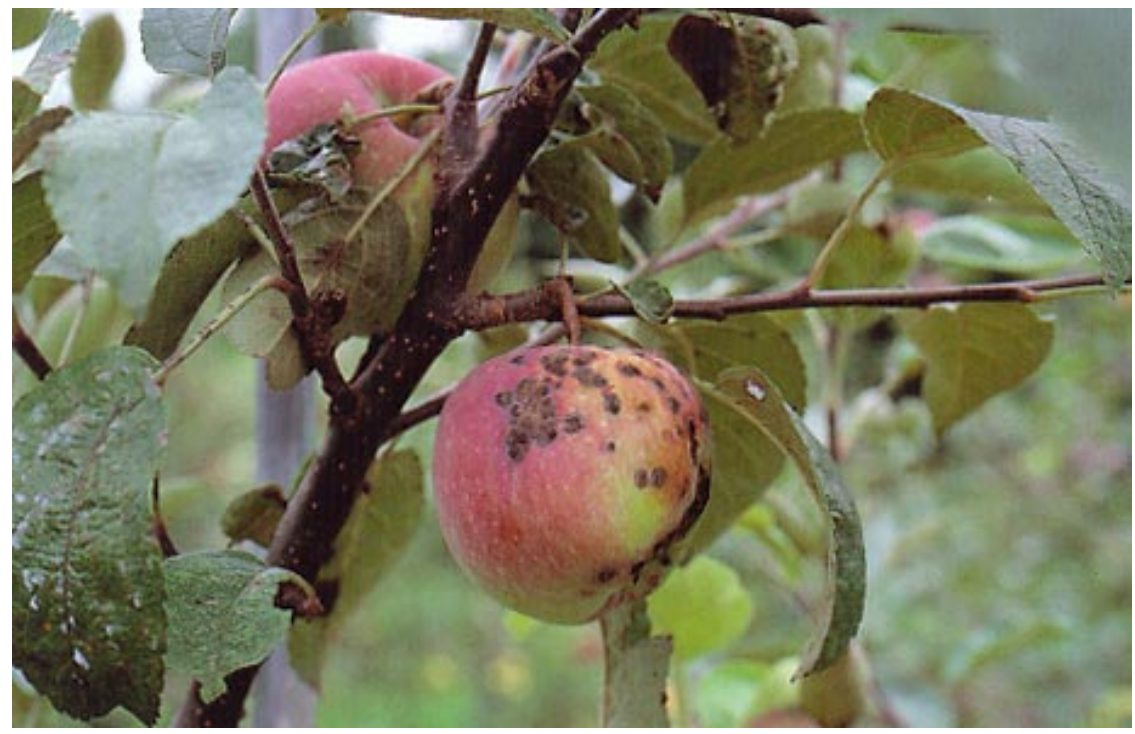

Fig. 1. Symptoms of apple scab.

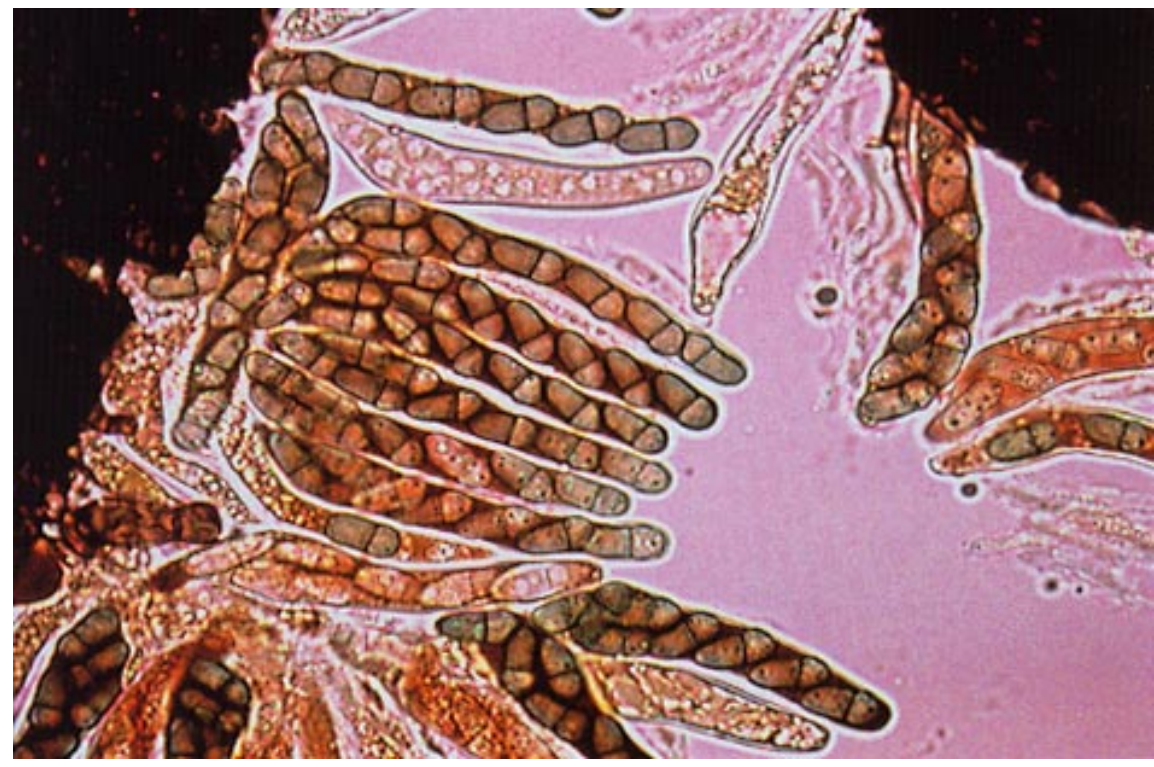

Fig. 2. Asci of Venturia inaequalis exposed by gently crushing a pseudothecium on a microscope slide (stained with a solution of iodine and potassium iodine); ascospores are approximately 6 by $13 \mu \mathrm{m}$. 
managed orchard in comparison to those originating from an outside source. This article describes some recent advances in modeling the aerial dispersal of the apple scab fungus. As an example, the model will be used to predict the probable numbers of scab infections occurring in an orchard due to ascospores originating in the orchard compared with those coming from an abandoned, heavily diseased orchard several kilometers away.

\section{Model Framework}

Our goal is to establish a mathematical model of ascospore dispersal that can be used to calculate probabilities of primary scab infection as the ascospore-release season advances from green tip through flower petal fall and early fruit development. Within this framework, we aim to relate the risk of scab infection to the amount of inoculum at the source, the stage (susceptibility) of developing fruit and vegetative buds, and weather factors.

The model combines several elements of meteorology and biology. Dispersal of apple scab by airborne ascospores is comprised of several parts (Sidebar). In order to quantify infection probabilities, aerobiological factors (3 through 6) must be combined with biological factors $(1,2,7$, and 8).

The risk of apple scab infection depends on the fraction of the total number of ascospores available for dispersal at a particular time. The total number available for the season depends on the amount of disease present at the end of the previous season, which can be expressed as a Potential Ascospore Dose, PAD $(29,40,44)$. Much less than this potential amount actually gets airborne (17), partly because of the physical and biological breakdown of source leaves and partly because some of the ascospores fail to escape from the ground cover. These levels are lowered further during aerial transport, since the concentration of ascospores in the air is reduced by wind shear, by turbulent diffusion, and by losses due to washout by rain. Wind shear, or the change in wind speed with

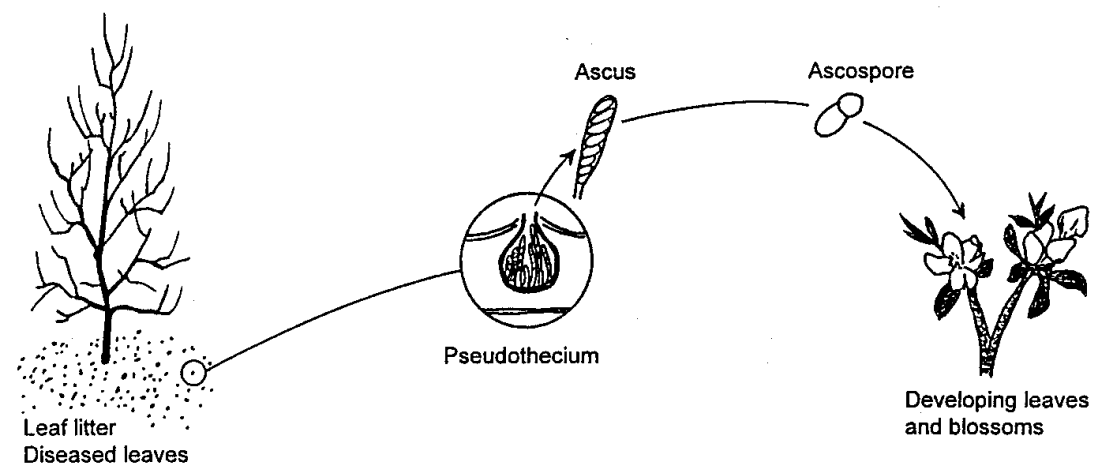

Fig. 3. The primary apple scab infection cycle. Ascospores released from diseased leaves on the ground from the previous growing season are carried by wind to newly developing apple tissues where infections can be initiated.
Susceptibility of apple leaves to scab infection and the lesion-causing efficiency of ascospores. The lesion-causing efficiency of ascospores $\left(I_{\mathrm{E}}\right)$ was determined in laboratory tests by inoculating individual leaves on vegetative shoots and fruit bud cluster leaves of potted apple trees (cv. Marshall McIntosh) with a known number of ascospores per unit leaf area $(2,16,47)$. On vegetative shoots, the most susceptible leaves were those that had been unfurled from the shoot for approximately 3 to 5 days. For these young, newly expanded leaves, it took about five asco-

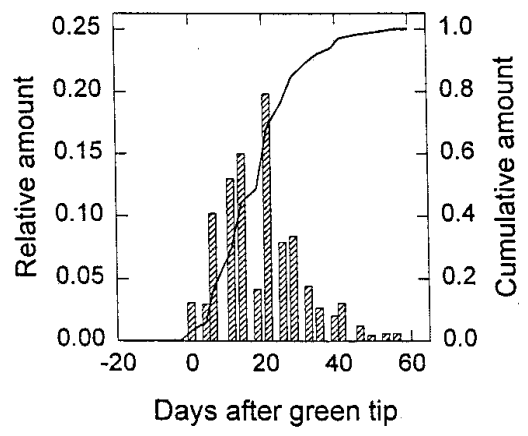

Fig. 4. Relative number of ascospores released in a laboratory spore tower (shown in Fig. 13) at various times during a season (bars) and the cumulative of the individual releases (line).

\section{Factors determining risk of infection from aerially dispersed spores (5)}

1. Spore production (inoculum amount)

2. Spore release

3. Escape from the surface or ground cover

4. Transport and dilution by turbulence

5. Loss of viable inoculum during transport

6. Deposition on host tissue

7. Area of host tissue per unit ground area

8. Infection efficiency of deposited spores (susceptibility of host tissue)

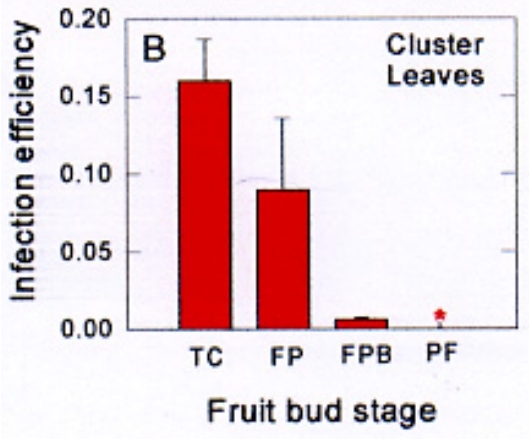

Fig. 5. Infection efficiency (actually lesion-causing efficiency) of Venturia inaequalis ascospores on vegetative shoot leaves (A) and fruit bud cluster leaves (B) at various times after bud break. Flower bud stages shown are: TC $=$ tight cluster, FP = first pink, FPB = full pink to bloom, and $\mathrm{PF}=$ petal fall.

Plant Disease / August $1998 \quad 839$ 
spores to cause one lesion (making $I_{\mathrm{E}}$ equal to about 0.2 lesions per spore). The susceptibility of leaves to infection decreased dramatically with increasing leaf age, in agreement with other studies $(25,49)$. It took nearly 70 ascospores to cause one lesion on leaves that had been unfurled from the bud for 12 days or more (Fig. $5 \mathrm{~A})$.

The growth of apple floral buds and cluster leaves encompasses several stages from dormancy to fruit set. During this development, leaves from floral buds undergo dramatic changes in size of tissue area and in susceptibility. The average infection efficiency of ascospores deposited on leaves from apple flower buds was about 16,9 , and $0.6 \%$ at tight cluster, first pink, and full pink-to-bloom, respectively (Fig. 5B). At petal fall, no lesions were observed on flower bud whorl leaves $\left(I_{\mathrm{E}}\right.$ was estimated to be $<0.1 \%$ ). These findings are in qualitative agreement with relative susceptibility values reported elsewhere (25).

Information on the temporal expansion of leaf area can be combined with values of $I_{\mathrm{E}}$ to estimate the amount of susceptible tissue area as a function of time. The area of cluster leaves initially increases, then levels off and remains nearly constant (Fig.
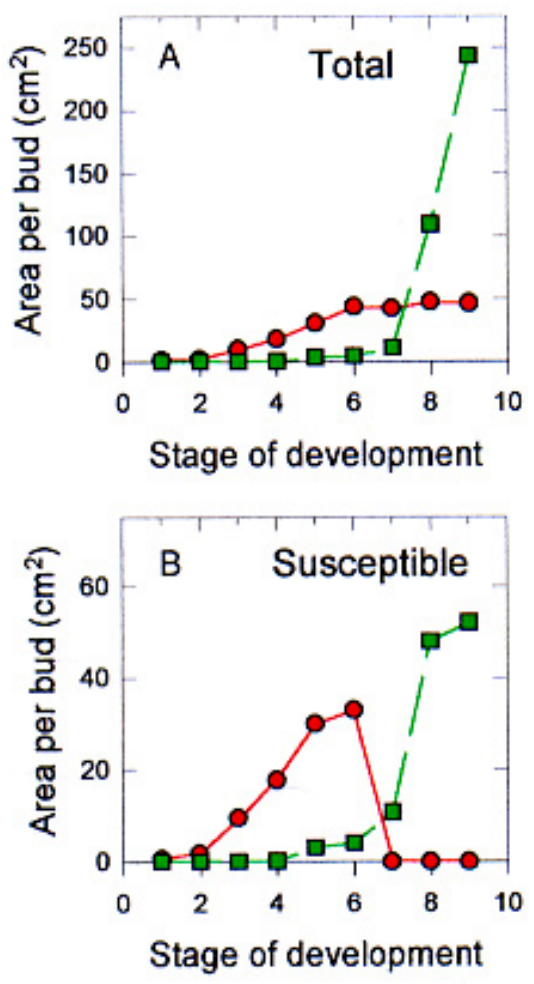

Fig. 6. The total leaf area (A) and susceptible leaf area (B) per bud for vegetative shoot leaves (green lines) and fruit bud cluster leaves (red lines) as a function of bud development stage. Bud stages 1 through 9 are: green tip, $1-\mathrm{cm}$ green, tight cluster, open cluster, pink, bloom, petal fall, $1-\mathrm{cm}$ fruit, $2-\mathrm{cm}$ fruit (22).
6A). At about the same time that cluster leaf susceptibility has declined to near zero, vegetative shoot area is increasing rapidly (Fig. 6A). Thus, although the amount of susceptible cluster leaf area decreases rapidly from bloom onward (Fig. $6 \mathrm{~B})$, the susceptible leaf tissue on the tree as a whole declines rather more slowly than this because of shoot development (Fig. 6B). The susceptibility of fruit is known to decline with age (50); however, quantitative inoculations to determine $I_{\mathrm{E}}$ for fruit tissue apparently have not been done (40). Our model can be easily modified to account for the susceptibility of any other apple cultivar by including the appropriate time course of tissue area expansion and $I_{\mathrm{E}}$ values as a function of age class for the cultivar in question. The area of susceptible apple tissue per unit ground area and the infection efficiency of ascospores will need to be determined for each cultivar and for different training systems. The calculations presented later in this article are based on leaf tissue of Marshall McIntosh apple trees and use the values of $I_{\mathrm{E}}$ given in Figure 5. Conditions for incubation in the field will generally not be optimal, and use of these values is expected to yield an upper (conservative) estimate of $I_{\mathrm{E}}$.

Combining the factors to estimate relative risk. During the season, the number of mature ascospores and the amount of susceptible tissue area increase at first, reach a peak, and then decline. Concurrently, the inoculum-harboring leaf litter on the ground breaks down over the course of the season due to mechanical and biological forces, effectively decreasing the inoculum supply during the season (11). The time course of changes in ascospore maturation, susceptible leaf area, and leaf litter can be combined in a simple model to generate a curve for relative risk of infection $(12,25)$. A comparison of this "relative

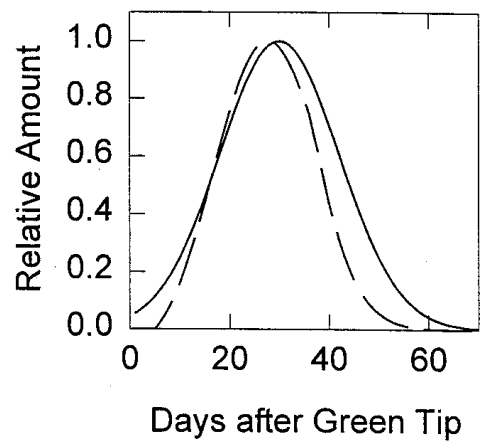

Fig. 7. Windows of opportunity for reducing control measures early and late in the ascospore release season made evident by comparing relative risk of scab infection (dashed line) with the relative availability of mature ascospores determined, e.g., by a laboratory spore release tower (solid line). risk" curve to the time course of the maturation of ascospores (Fig. 7) suggests that chemical control measures might be reduced during "windows of opportunity" both in the early and the late part of the ascospore release season. However, actual, not relative, risk is what really matters for disease control. Actual risk depends on the amount of overwintering inoculum and its relationship to the concentration of ascospores in the air in the orchard. The mathematical model of spore dispersal described herein can be used to obtain an estimate of actual risk.

Seasonal variation of ascospore maturation and release. Several methods are used to try to determine the beginning and end of the ascospore release season. In one method, the fungus fruiting bodies (pseudothecia) are removed from a leaf using a scalpel, squashed gently on a slide, and examined using a microscope. These "squash mounts" allow a count of the number of mature ascospores present at the time the sample was collected $(27,54)$. Interpretation of squash mounts requires considerable skill and is not completely straightforward (31). Another method involves collecting leaves from the orchard and wetting them in the laboratory to initiate ascospore release. The released spores are trapped either in water or on a sticky surface in a spore release tower and counted under a microscope. The third and most direct method is to monitor actual airborne ascospore concentrations in the orchard using a spore sampler, such as a Burkard volumetric sampler.

Substantial differences are apparent between the temporal pattern (time course) of airborne ascospores above a source in the field and the pattern of spore release obtained from samples of source leaves induced to release spores in laboratory tests (11). The cumulative number of ascospores collected in the laboratory tests tends to lag behind the cumulative number of ascospores sampled in the air above the source in the field (Fig. 8). The laboratory method indicates a longer ascospore release season than actually occurs in the

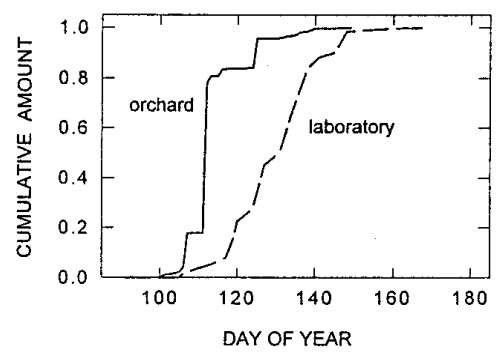

Fig. 8. Cumulative relative release of ascospores over the course of the season determined by sampling air in an orchard (solid line) and by spore tower releases in the laboratory from diseased leaves collected from the same orchard (dashed line). 
field. During 4 consecutive years of tests, the date when half of the season's total ascospores was released in the laboratory tests lagged behind the half-way point for airborne spores in the field by $7,18,11$, and 14 days. Thus, the dispersal potential of $V$. inaequalis ascospores in the field is less than would be expected from the laboratory tests.

Part of this lag (delay) can be explained by a fundamental difference between the laboratory and field measurements. The laboratory spore tower method measures the rate of release of ascospores per leaf, $Q_{\mathrm{L}}$, while the Burkard spore sampler monitors the release rate per unit ground area, $Q$. The link connecting the two release rates, $Q$ and $Q_{\mathrm{L}}$, is the number of leaves per unit ground area in the field, $N_{\mathrm{L}}(t)$. In particular, the release of ascospores per unit ground area is proportional to the product of the release rate per leaf and the number of inoculum-harboring leaves per unit ground area of the source, i.e., $Q \propto Q_{\mathrm{L}} \times N_{\mathrm{L}}(t)(11)$. In the experiments referred to above, $N_{\mathrm{L}}(t)$ decreased with time during the ascospore release season. When the decline in $N_{\mathrm{L}}$ was taken into account, about half the lag between the laboratory and field measurements disappeared. The remaining difference is intriguing. One possible explanation, which involves the escape of ascospores from the ground cover canopy, will be discussed in a later section.

The results given in Figure 8 suggest the possibility of shortening the primary scab control season. Caution is warranted, however, because these findings indicate relative (not actual) risk of infection. Relaxation of control measures may not be warranted if inoculum levels are high in the orchard or in neighboring areas. Needed is a quantitative model of ascospore dispersal to improve our ability to estimate actual risk of scab infection.

\section{Aerial Spore Concentration}

Exposure to airborne ascospores and disease development. Earlier studies have shown that the number of primary apple scab infections can be related quantitatively to the aerial concentration of ascospores in the air surrounding susceptible apple leaf tissue (16). Potted "sentinel" trees (cv. McIntosh) were exposed to ascospores released naturally in an orchard during rainfall. The aerial concentration of $V$. inaequalis ascospores, $C$ (ascospores $\mathrm{m}^{-3}$ ), was determined next to the sentinel trees using Rotorod spore samplers (8). The exposed trees were removed from the field, incubated in a dew chamber, and maintained in a growth room until lesions developed.

A spore dispersal model was used to estimate the number of ascospores deposited per unit area onto leaves for a given exposure to $C$ (16). The number of deposited ascospores was converted to an expected number of scab lesions using the lesioncausing efficiency, $I_{\mathrm{E}}$, of $V$. inaequalis ascospores as previously described (Fig. 5). The number of lesions that developed on the sentinel trees was related quantitatively to the exposure to ascospores (Dose $=C \times$ time $)$. The numbers of lesions estimated using the model were correlated well ( $r=0.83, P<0.01)$ with the number of lesions actually found on the trees exposed in the field.

The lesion-causing efficiencies of ascospores under field conditions are likely to be lower than those found under the favorable laboratory conditions of our experiments. Therefore, the values of $I_{\mathrm{E}}$ used here (Fig. 5) will make the model conservative from the point of view of the grower, in that it will tend to overpredict rather than underpredict the number of lesions expected from a given exposure.

These studies show that the number of primary apple scab infections depends directly on the concentration of ascospores in the air surrounding the developing (and susceptible) apple tissue. As long as inoculum levels are well below levels that would saturate the available infection sites (34) (as they are expected to be in a commercial orchard), the model can be used to estimate the number of infections if $C$ is known in the orchard canopy. To realize our goal of being able to predict infection probabilities from knowledge of the inoculum source strength alone, we needed a way to predict $C$; for this, some equations and some notations (Sidebar) must be introduced. The good agreement with field observations described above encouraged us to take this next step in developing the model.

Model equations. The number of $V$. inaequalis ascospores that will be deposited on host tissue depends on the concentration of ascospores, $C$ (ascospores $\mathrm{m}^{-3}$ ), in the air surrounding the host tissue. An ability to predict $C$ is central to further progress in our modeling efforts. In the case of apple scab, $C$ is the physical link between ascospore inoculum that develops on leaves overwintering on the ground and the potential for initiating apple scab infections (Fig. 3).

Spore concentration decreases rapidly with height above the ground and with increasing downwind distance from a source (Fig. 9). The rapid decrease of $C$ with increasing distance and height is due to wind shear, turbulent diffusion, and losses due to washout by rain $(4,10)$.

$V$. inaequalis ascospores are released into the air at ground level. Once airborne, they are simultaneously transported downwind by the horizontal motion of the wind

\section{Definition of Symbols}

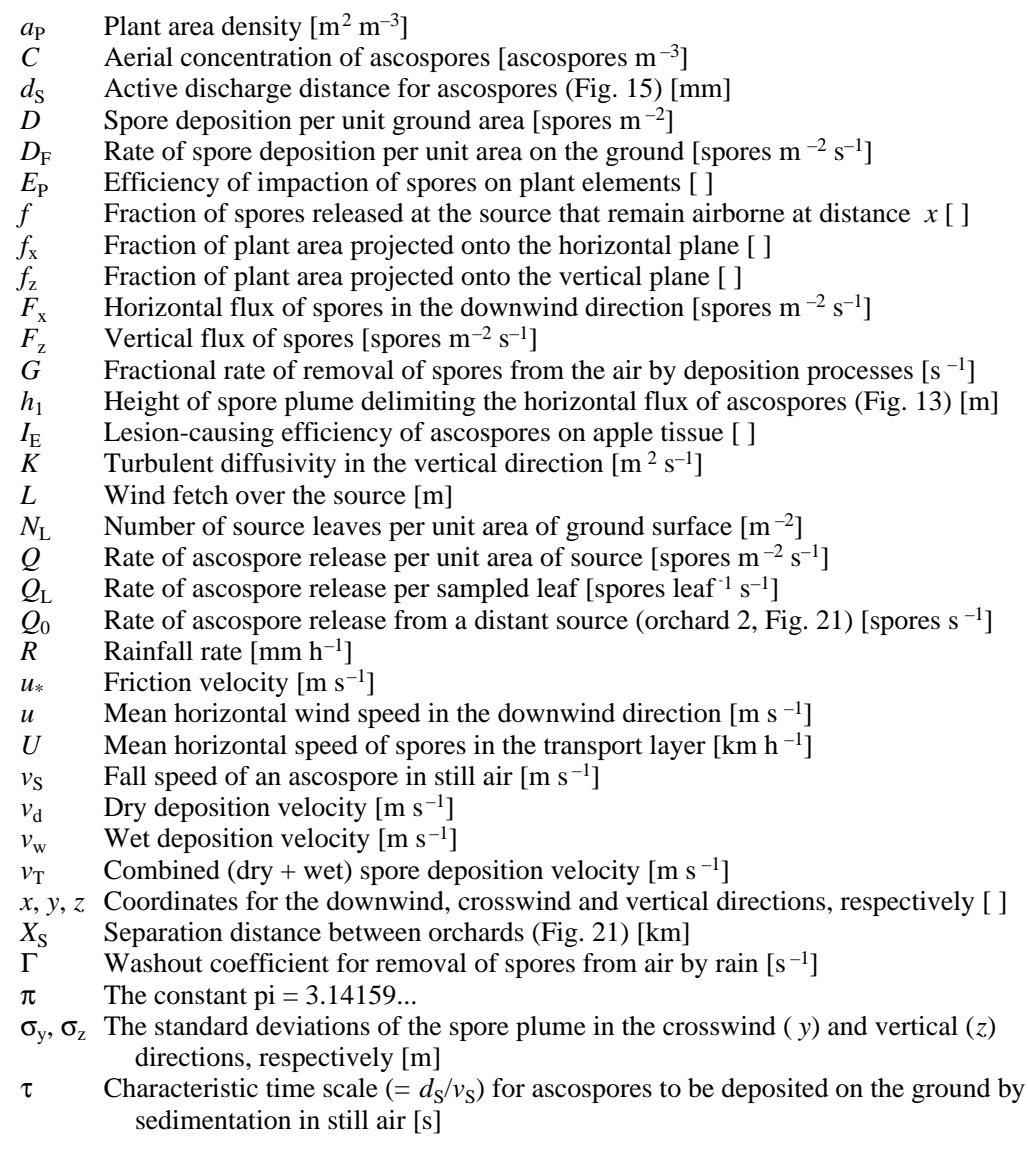

Dimensionless quantities indicated by open square brackets [ ] following the explanation. 
and diffused vertically by the turbulent fluctuations of the wind. A portion is also deposited on the vegetation and ground in the orchard. The change of $C$ with downwind distance and height above the ground can be described by an equation that expresses the conservation of the numbers of airborne ascospores (Fig. 10). Assuming that the source extends infinitely far in the crosswind direction and that conditions are steady, an equation for $C$ can be written as (10):

$$
u(z) \frac{\partial C(x, z)}{\partial x}=\frac{\partial}{\partial z}\left[K(z) \frac{\partial C(x, z)}{\partial z}+v_{S} \cdot C(x, z)\right]-G(z) \cdot C(x, z)
$$

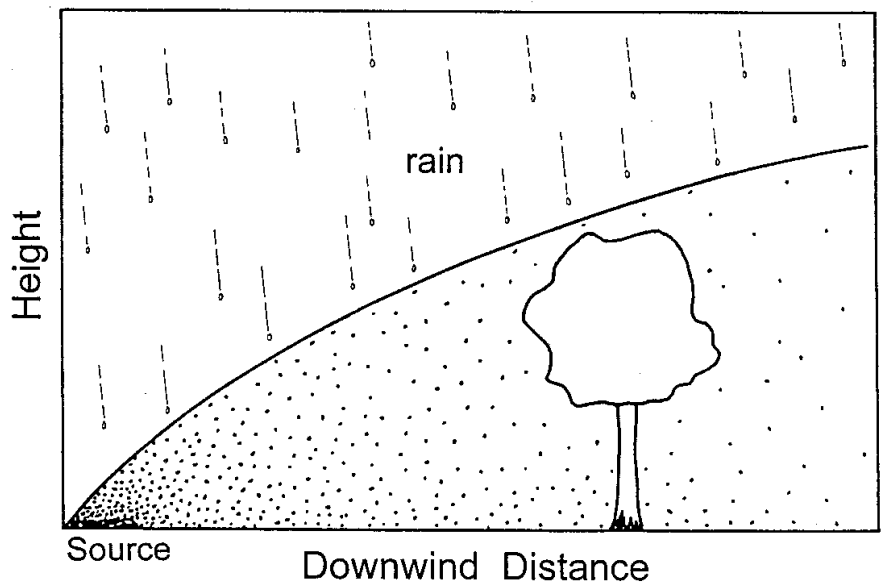

Fig. 9. Illustration of the decrease in aerial concentration of ascospores with increasing height above and with increasing distance downwind of a source of ascospores. The "tree" can be imagined to be either within an orchard block, on another part of the farm, or on a distant farm.

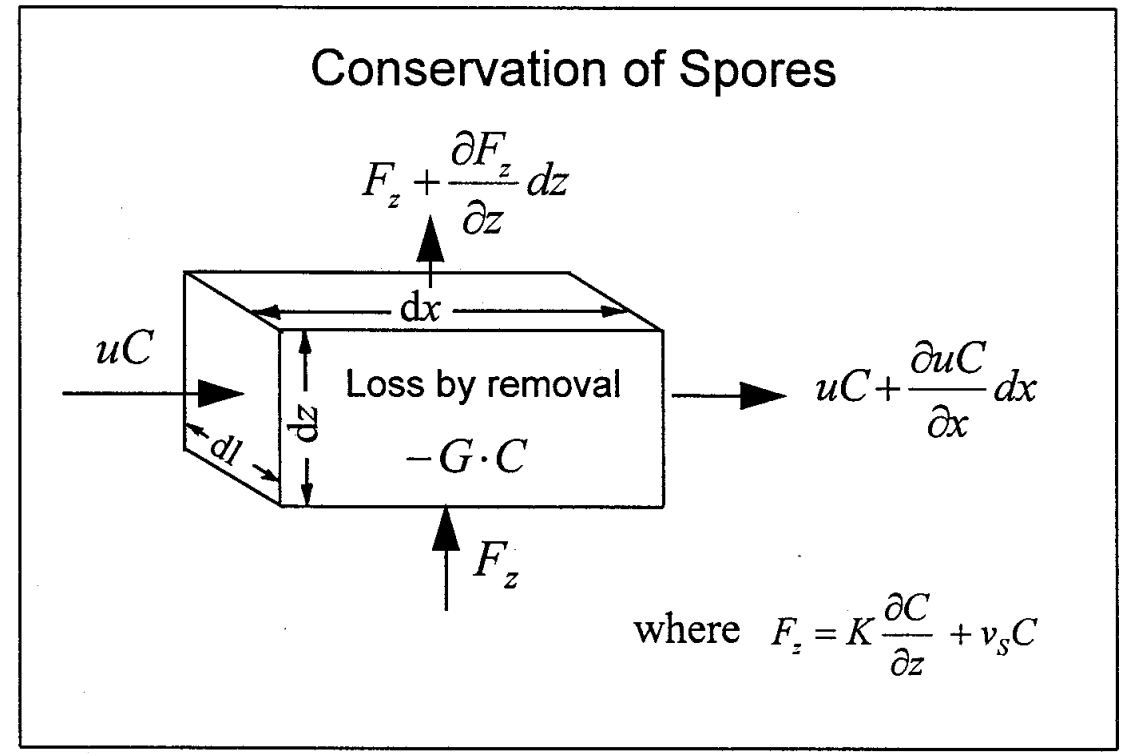

Fig. 10. Illustration of the mathematical balance for ascospores that are carried into and out of a small "differential" size box horizontally by air flow and vertically by turbulent diffusion and sedimentation. The box has dimension $\mathrm{dx}$ in the horizontal, $\mathrm{dz}$ in the vertical, and unit length dl into the plane of the paper. Equation 1 is an expression of the conservation of mass and arises from the difference of the horizontal and vertical fluxes of spores into and out of the box (see arrows) and the decrease in airborne spores inside the box due to their removal by deposition on apple trees and by washout by rain. Wind speed $u$ is assumed to be constant in the $x$ direction and has been taken outside the derivative in equation 1. still air. $V$. inaequalis ascospores are about $6 \times 13 \mu \mathrm{m}$ and have a settling speed in still air of about $0.002 \mathrm{~m} \mathrm{~s}^{-1}(34)$. As written, equation 1 does not account for diffusion in the crosswind direction. For the numerical example to be presented later, our attention will be restricted to points along the centerline of the orchard in the direction of the wind where equation 1 does yield good estimates of $C$ and spore deposition.

The removal rate $G$ includes washout by rain (19) and deposition on plants and the ground $(4,15)$. Ascospores can be deposited onto plant surfaces either by raindrops containing ascospores or by impaction and sedimentation of ascospores that are contained in the air $(16,17,19)$. In the volume of air containing the orchard trees, $G$ can be expressed as:

$$
G(z)=\Gamma+\left[v_{S} \cdot f_{X}+u(z) \cdot E_{P} \cdot f_{Z}\right] \cdot a_{P}
$$

while above the tree tops, $a_{\mathrm{P}}=0$ and there $G(z)$ is simply equal to $\Gamma$. In equation 2 , $\Gamma\left(\mathrm{s}^{-1}\right)$ is the washout coefficient for removal of ascospores by rain (19), $f_{\mathrm{X}}$ and $f_{\mathrm{Z}}$ are, respectively, the fractions of the plant area projected onto the horizontal and vertical planes, $u(z)$ is the time-averaged horizontal wind speed, $E_{\mathrm{P}}$ is the efficiency of inertial impaction of ascospores in the air onto plant elements, and $a_{\mathrm{P}}\left(\mathrm{m}^{-1}\right)$ is the density of projected plant area per ground area. The first term on the right-hand side of equation 2 represents removal by rain, the second term represents gravitational settling onto orchard trees, and the third term represents the contribution of inertial impaction of "dry" spores onto the trees. Equations 1 and 2 can be solved, subject to

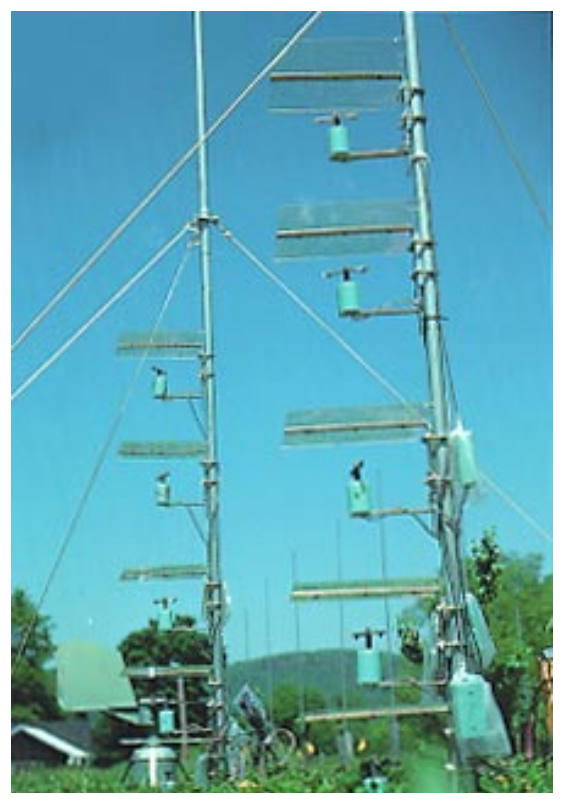

Fig. 11. Vertical arrays of rotorod spore samplers used to measure the variation of ascospore concentration with height above the ground. 
appropriate boundary conditions (10), using standard numerical techniques to give values of $C(x, z)$.

The model results were compared to values of $C$ determined at several heights above the ground in a young orchard of dwarf apple trees using Rotorod samplers (Fig. 11). The model described the general shape of the observed concentration profiles (Fig. 12) reasonably well (10). Early in the growing season, an orchard (particularly an orchard of dwarf apple trees) is mainly just a bunch of sticks, and a sparse one at that. The plant area density is less than $1 \%$ of typical values of the leaf area density of row crops such as wheat or corn (16). Because of this low density in the tree canopy volume, there is relatively little resistance to air movement. This allows the use of relatively simple descrip-

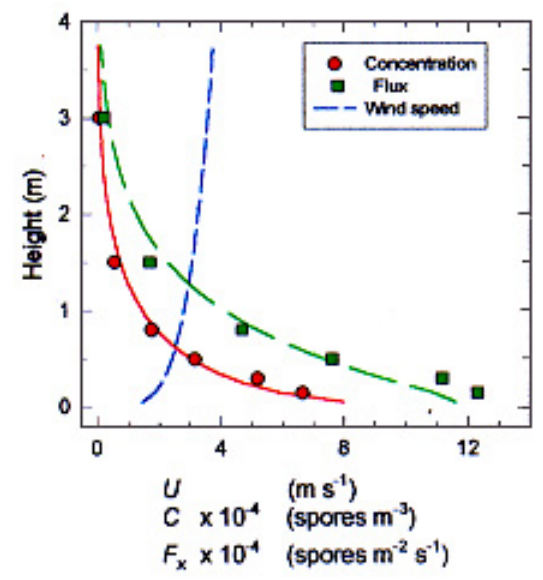

Fig. 12. Typical vertical profiles of ascospore concentration (red line and circles), wind speed (blue dashed line), and the corresponding model-derived horizontal flux of ascospores (green line and squares). tions of wind speed and eddy diffusivity in the model during the majority of the ascospore release season. To model ascospore releases that occur late in the season when the foliage on the trees is more fully developed, we will require more complex descriptions of $u$ and $K$, or a different model formulation altogether (see below).

The strong similarity of the shapes of the spore concentration $(C)$ profiles observed for different sampling periods (10) reflects the underlying generality of the physical laws governing the transport and dilution of airborne ascospores embodied in equation 1. During conditions of light wind, the model tends to underpredict relative values of $C$ both near the ground and near the top of the trees. To improve model performance during light wind and rain, we will need to have a better description of wind speed and turbulent eddy diffusivity under these conditions.

Quantitative relationship between spore release rate and number of spores in the air. The main factor limiting our ability to quantify the aerial transport and deposition of pathogen inoculum is our inability to quantify the rate of spore release, $Q$, from a source. We recently demonstrated that the integrated horizontal flux (IHF) micrometeorological method $(17,24,56)$ can be used to estimate $Q$ for naturally released $V$. inaequalis ascospores. A relationship was established between the amount of inoculum in source leaves overwintering on the ground and the concentration of ascospores in the air using two independent methods. In one method, a laboratory spore release tower was used to determine the number of ascospores released from source leaves sampled throughout the season. The spore release tower consisted of a vertically oriented wind tunnel and volumetric spore samplers
(Fig. 13A). Ascospore release rate in the tower, $Q$, was determined twice weekly from leaves freshly collected from the source.

In the second method, vertical profiles of $C$ and $u$ were measured in the field above a source. Rotorod spore samplers were used to determine ascospore concentrations, and anemometers were used to measure wind speeds at several heights above the ground near the center of the source (Fig. 13B). The spore concentration and wind speed values were multiplied to yield corresponding values of the horizontal flux of ascospores, $F_{\mathrm{X}}(z)$ (Fig. 12). The vertical integration of $F_{\mathrm{x}}$ yields a direct measure of the number of ascospores released from the source at locations upwind of the spore samplers.

The IHF method can be used to measure $Q$ because the number of ascospores is a conservative quantity. That is, airborne ascospores are neither created nor destroyed, but rather, they are either deposited or transported past our sampling tower by the wind. Consider spores released at ground level from an area source that extends infinitely far perpendicular to the direction of the wind. In the absence of a plant canopy, the cumulative release of spores (less spore deposition $D$ ) between the upwind edge of the source $(x=0)$ and the downwind location of the spore samplers $(\mathrm{x}=L)$ is equal to the vertically integrated horizontal flux of spores at $\mathrm{x}=L$ and can be expressed as:

$$
\int_{0}^{L}[Q(x)-D(x)] d x=\int_{0}^{h_{1}} u(z) \cdot C(L, z) d z
$$

The integral of $[Q(x)-D(x)]$ is the cumulative number of spores released from the source less those deposited on the ground, $L$ is the fetch of the wind over the source, and $h_{1}$ is a height above the top of

\section{SPORE RELEASE TOWER}

\section{AIRBORNE FLUX OF SPORES}
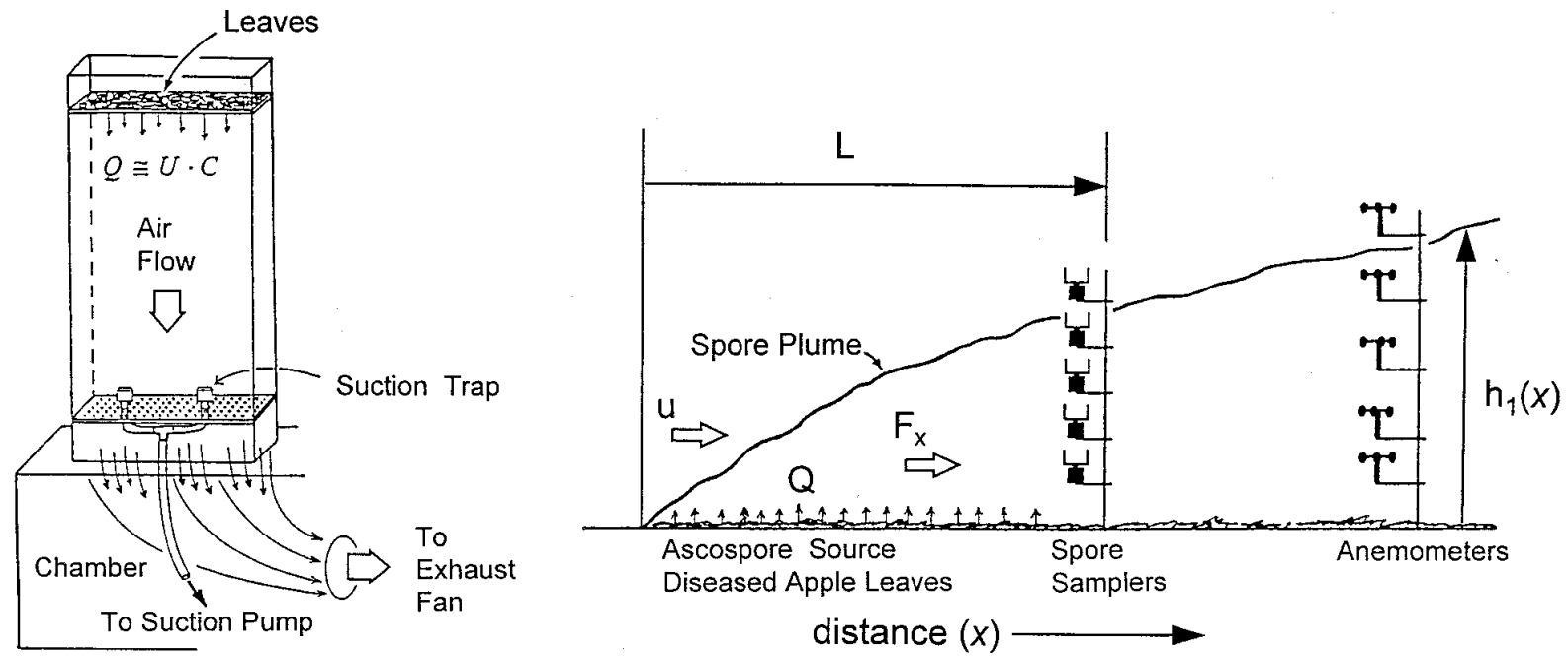

Fig. 13. Schematics of the laboratory spore release tower method (left) and the field micrometeorological integrated horizontal flux method (right) for determining the release of Venturia inaequalis ascospores from a source. 
the spore plume for which vertical transport of spores is zero. This equation states that the cumulative number of spores released from the ground (less deposition) between $x=0$ and $L$ is equal to the number carried by the horizontal component of the wind through the vertical plane at $L$, between the heights $z=0$ and $z=h_{1}$.

A good correlation was found between the flux of ascospores measured in the field and the number of ascospores released in the laboratory spore tower at corresponding times (17). The two methods yielded values for the cumulative total seasonal release of ascospores which agreed well (Fig. 14) for sources in a grass field and in an orchard of dwarf apple trees (to within a factor of two for a source in a grass field and to within a factor of three for a source in an orchard of dwarf apple trees). The good agreement between the micrometeorological field method and the biological laboratory method was encouraging for further development of the spore dispersal model.

Escape of ascospores from a grass canopy. To paraphrase an ancient Chinese proverb "a journey (of a thousand miles) must begin with a single step." To become airborne, ascospores must first leave the ascus. Discharge distances of $V$. inaequalis ascospores were measured in a small chamber designed to eliminate air currents (Fig. 15) (13). Because of their small size, actively discharged ascospores follow a squared-off "sporabolic" path (21). The great majority of $V$. inaequalis ascospores are propelled less than $1 \mathrm{~cm}$ into the air, and fully half are ejected less than $3.5 \mathrm{~mm}$ (Fig. 15). In view of these small distances,
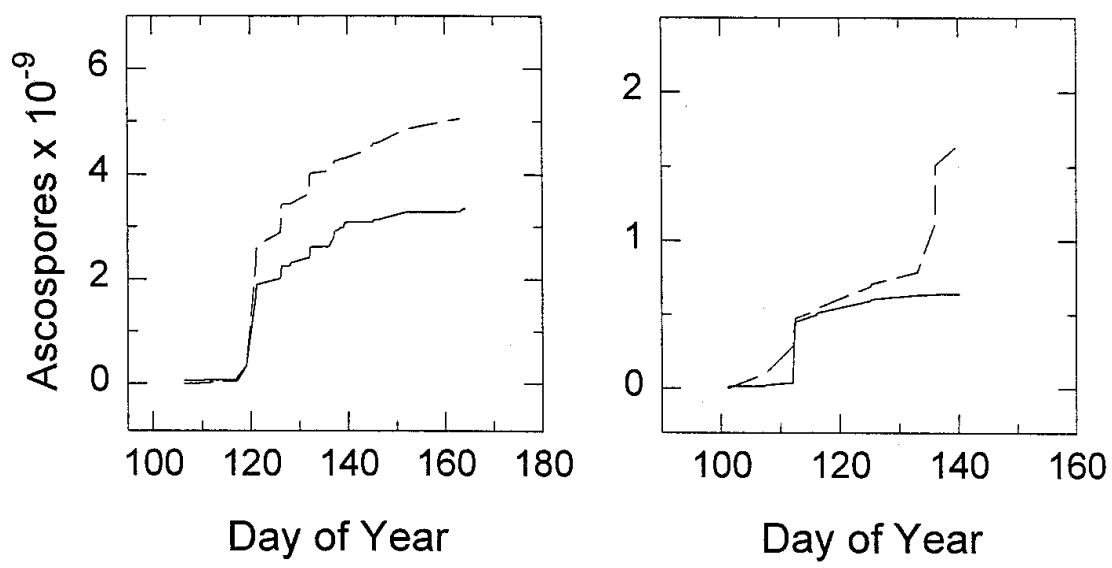

Fig. 14. Comparison of the cumulative number of ascospores determined using the micrometeorological field method (solid lines) and that determined using the laboratory spore tower method (dashed lines). The left panel shows results for a source in a grass field and the right panel for a source in an orchard. it is reasonable to ask if a ground cover canopy could significantly reduce the escape of ascospores into the more freely moving air above, a thought that is reinforced by taking a ground-level view of the rotorod towers through a grass ground cover (Fig. 16).

Wind in a grass canopy. The likelihood that ascospores will escape from the layer of relatively still air near the ground beneath an orchard ground cover canopy depends largely on the turbulence of the wind. Hot-wire and hot-film anemometers were used during fair weather to characterize the wind in a canopy of tall fescue grass (Festuca arundinacea) (20). Average wind speeds measured at $1 \mathrm{~cm}$ above the ground ranged from 1 to $7 \mathrm{~cm} \mathrm{~s}^{-1}$ and, on average, were about $11 \%$ of the friction velocity, $u_{*}$. Friction velocity is a measure of atmospheric turbulence generated by wind shear near the ground and is used to scale wind speed and turbulent fluctuations near the ground (3). Lulls in the wind, when wind speed was slower than 1 to 2 $\mathrm{cm} \mathrm{s} \mathrm{s}^{-1}$, were observed rarely, and when they occurred they tended to last less than $1 \mathrm{~s}$.

Characteristics of the wind near the ground during rain. $V$. inaequalis ascospores become airborne primarily during rain, and we need to know wind statistics that are applicable during rain. Hot-film anemometers and a 3-D sonic anemometer were used to measure wind speed fluctuations above short grass during rain (14). A filtering algorithm was devised to identify in the anemometer signals spikes that were induced by raindrop impacts on the hotfilm sensors or by water collected on the sonic sensors. A relatively small number of such spikes, comprising only about 0.1 to

\section{SPORE DISCHARGE CHAMBER}

\section{SPORE DISCHARGE DISTANCE}
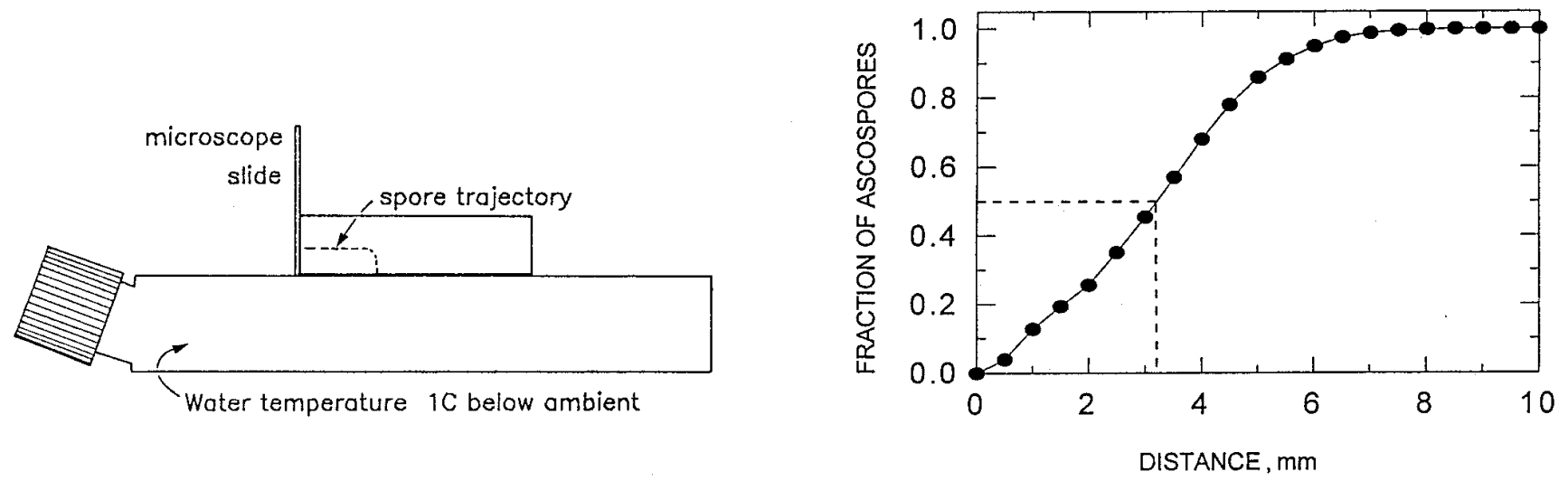

Fig. 15. Schematic of the spore discharge chamber (left) used to measure the active discharge distance of Venturia inaequalis ascospores (right). A small piece of an apple leaf with pseudothecia containing mature ascospores is excised, wetted, and adhered to a microscope slide with a small drop of water (13). The leaf piece is placed on the slide so that it is centered in the opening of the chamber when the slide is placed vertically over the open end of the $1-\mathrm{cm}$-high by $2.3-\mathrm{cm}$-wide by $5.0-\mathrm{cm}$-long discharge chamber. Ejected ascospores are deposited on a 22 by $50 \mathrm{~mm}$ coverslip placed in the bottom of the chamber. Convection currents are essentially eliminated by the shallow height of the chamber (13). The slant-neck flask containing water at $1^{\circ} \mathrm{C}$ below ambient temperature acts as a heat sink and helps to maintain the floor of the chamber at a slightly lower temperature than the chamber roof to avoid any slight tendency for convection currents inside. 
$0.2 \%$ of the data, occurred in signals recorded during rainfall rates ranging from $<0.1$ to $7.2 \mathrm{~mm} \mathrm{~h}^{-1}$. After these spikes were removed from the time series by filtering, the resulting values of the first four moments of wind speed (i.e., mean, variance, skewness, and kurtosis) were very similar to those found above grass during fair weather. Moreover, the relationships between the fluctuations in vertical and horizontal components of wind speed and momentum flux (as indicated by $u_{*}$ ) were in good agreement with those found during conditions of fair weather and near-neutral atmospheric stability. Thus, for purposes of modeling the initial aerial dispersal of $V$. inaequalis ascospores, it is reasonable to use the description of atmospheric diffusivity determined in studies during fair weather, of which there are many.

In summary, the wind during the daytime is highly intermittent and characterized by relatively long quiescent periods (lulls), interrupted by the occasional penetration of strong gusts down into the canopy. At a height of $1 \mathrm{~cm}$ above the ground, the average length of time that wind speed drops below the mean wind speed at that height is about $2.3 \mathrm{~s}$. Lulls marked by a threshold of one-third of the mean speed lasted less than $1 \mathrm{~s}$, on average.

Modeling spore trajectories near the ground. A characteristic time scale for ascospores to be deposited on the ground by sedimentation is $\tau=d_{\mathrm{s}} / v_{\mathrm{s}}$, where $d_{\mathrm{s}}$ is the distance that ascospores are energetically projected into the air by the fungus and $v_{\mathrm{s}}$ (equal to $0.002 \mathrm{~m} \mathrm{~s}^{-1}$ ) is the settling speed of the spore in still air. Values of $d_{\mathrm{s}}$ for $V$. inaequalis ascospores are between 3 and $7 \mathrm{~mm}$ (Fig. 15), leading to values of $\tau$

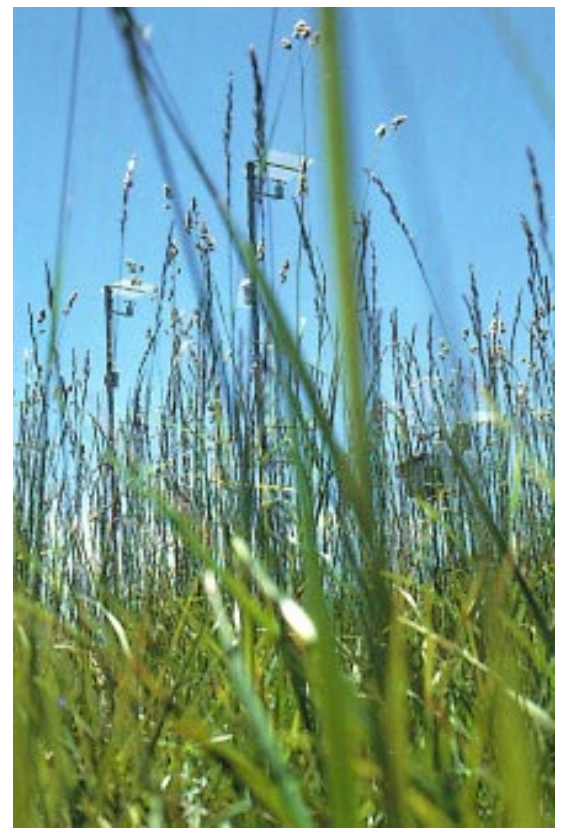

Fig. 16. Rotorod tower as seen through grass from the eye level of a meadow vole. in the range 1.5 to $3.5 \mathrm{~s}$. Lulls in the wind, which last for $3 \mathrm{~s}$ or more, are rare; their average length is closer to $1 \mathrm{~s}$, which is less than the length of time critical for depositing $V$. inaequalis ascospores by sedimentation. Therefore, lulls do not generally last long enough, nor are they frequent enough, to significantly enhance the deposit of $V$. inaequalis ascospores by sedimentation. In other words, $V$. inaequalis ascospores will not all settle out of the air during lulls in the wind.

Once ascospores are airborne, we can model their movement using a Lagrangian Simulation (LS) model (i.e., a random flight spore trajectory simulation model) $(6,7,9,26,55,57)$. This model uses the average wind statistics in the grass canopy and describes the motion of individual spore trajectories (Fig. 17). The motions of many individually released spores are simulated, and the results of each simulation are combined to describe an entire release event. The simulation model accounts for spore deposition on the ground and on the grass in the ground cover canopy. Although the grass appears rather dense from a meadow vole's viewpoint (Fig. 16), it would seem relatively sparse from the point of view of a spore (Fig. 18). The probability of a spore being deposited at each time step is calculated using a form of equation 2 , with the appropriate substitution of parameters for the grass canopy. The simulations suggest that the percentage of ascospores that

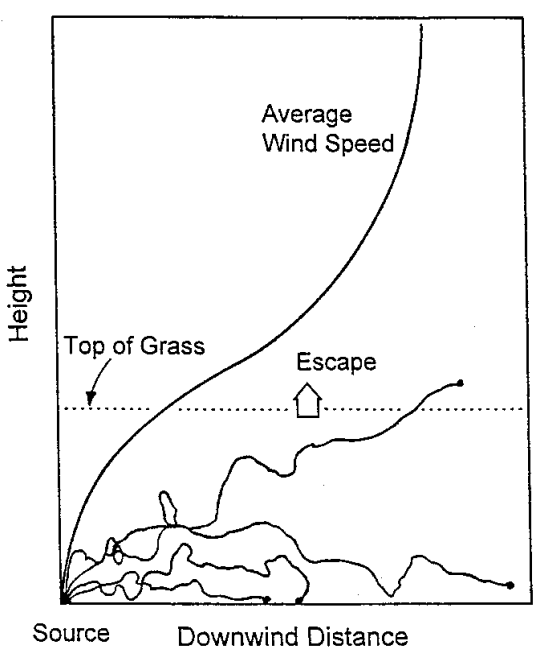

Fig. 17. Simulated trajectories of ascospores obtained by a Lagrangian sporeflight simulation model. Grass reduces air movement near the ground where the ascospores are released, allowing them more time to be deposited. Spores that pass upward through the plane at the top of the grass canopy (dotted line) escape from the canopy. A small portion of these "escaped" spores can return to the canopy, but most are transported upwards and away by turbulent wind where they have the possibility of encountering host tissue. escape from the canopy is highly sensitive to wind speed above the canopy. For a 0.5 $\mathrm{m}$ tall grass canopy, simulated escape varies between about 30 and $75 \%$ for friction velocities, $u_{*}$, between 0.1 and $0.5 \mathrm{~m} \mathrm{~s}^{-1}$ (Fig. 19). Escape should be least during stable nighttime conditions, when $u_{*}$ is small (3). Relatively few $V$. inaequalis ascospores are released at night $(19,42)$, an obvious advantage for the fungus.

Armed with these results, we can return to examine a possible reason for part of the difference between the field and laboratory methods for indicating the end of the ascospore release season (Fig. 8). Recall that about half of the difference between the curves can be explained by the natural decline in the number of source leaves on the ground as the season progresses. At least some of the remainder can be explained by retention of ascospores in the ground cover. To be sure, a grass ground cover, with a $50 \%$ retention of spores, is not likely to be an important factor in the management of apple scab during most of the season when inoculum levels are very high. However, retention in ground cover might contribute significantly at the end of the season when inoculum levels are only marginally too high. Field experiments and modeling efforts are currently underway to determine the magnitude of this effect. The results should allow us to examine whether or not letting the grass grow tall in an or-

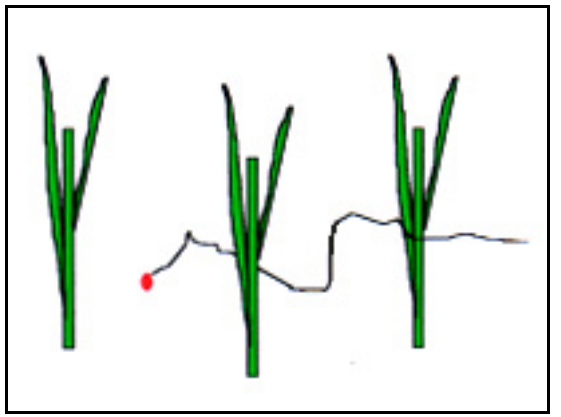

Fig. 18. A spore's eye view of the grass. From a spore's point of view, the grass is rather sparse.

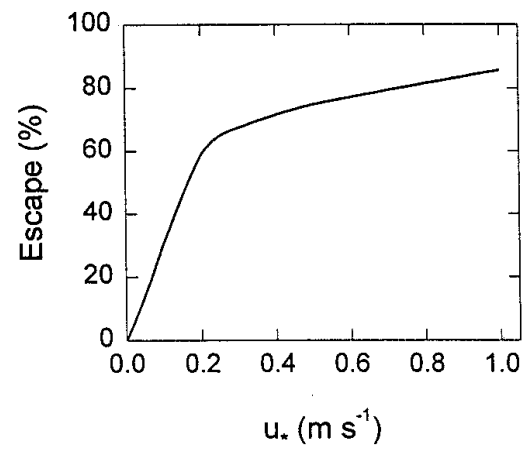

Fig. 19. Escape of ascospores from a grass canopy (as a percentage of the number released) versus friction velocity $u_{*}(3)$. 
chard can effectively shorten the primary scab infection season by trapping ascospores before they become airborne.

Long distance (between orchards) spore transport. To predict the possible dispersal of apple scab between orchards, we employed a Gaussian plume model $(4,34,46)$ to calculate ascospore concentration $C$ as a function of distance from a source. $C$ decreases with distance from a source because of dilution due to atmospheric turbulent diffusion and to deposition and washout of spores during transport. Ascospores are removed from the air and deposited on apple tissue by a combination of wet (washout) and dry deposition processes. $V$. inaequalis ascospores settle slowly $\left(\sim 2 \mathrm{~mm} \mathrm{~s}^{-1}\right)$. Washout contributes substantially to ascospore deposition, and its relative importance (compared with dry deposition) increases with distance from a source. This is because dry deposition is limited to the removal of spores near the ground, while wet deposition can remove spores from the entire depth of the spore cloud, which spreads out with increasing distance from a source.

Gaussian plume. The deposition flux $D_{\mathrm{F}}(x)$ (spores $\mathrm{m}^{-2} \mathrm{~s}^{-1}$ ) of spores to the ground at a downwind distance $x$ from a source can be expressed as the product of a deposition rate $v_{\mathrm{T}}\left(\mathrm{m} \mathrm{s}^{-1}\right)$ and the aerial concentration $C$ (spores $\mathrm{m}^{-3}$ ) of spores $(4,19,23,48,51)$ :

$$
D_{F}(x, y, 0)=v_{T} C(x, y, z)
$$

where $v_{\mathrm{T}}$ includes both wet $\left(v_{\mathrm{w}}\right)$ and dry $\left(v_{\mathrm{d}}\right)$ deposition processes (19). The total number of spores deposited per area of ground during a transport event, $D$ (spores $\mathrm{m}^{-2}$ ), is obtained by integrating $D_{\mathrm{F}}$ over the length of time that the plume of spores is over a location.

For relatively large distances from a source $(1 \mathrm{~km}<x<10 \mathrm{~km})$, it is appropri-

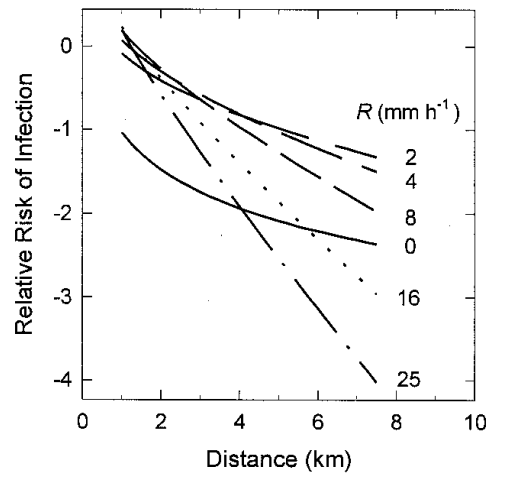

Fig. 20. An illustration of the relative risk of apple scab infection versus distance from a source calculated using the model (equations 4 and 5) with wind speed, $U$, constant at $10 \mathrm{~km} \mathrm{~h}^{-1}$. Risk is a strong function of rainfall rate, $R$, shown by the various curves where $R$ (measured in $\mathrm{mm} \mathrm{h}^{-1}$ ) is a parameter. ate to represent $C$ in equation 4 by a Gaussian plume model (51). The concentrations $C(x, y, z)$ given by the Gaussian plume model for spores released at ground level can be expressed as $(4,23,51)$ :

$$
\begin{aligned}
C= & {\left[f(x) Q_{0} /\left(\pi U \sigma_{y} \sigma_{z}\right)\right] . } \\
& \exp \left(-y^{2} / 2 \sigma_{y}^{2}\right) \exp \left(-z^{2} / 2 \sigma_{z}^{2}\right)
\end{aligned}
$$

where $Q_{0}$ (spores $\mathrm{s}^{-1}$ ) is the rate of release of spores at the source, $f(x)$ is the fraction of $Q_{0}$ remaining airborne at $x, \sigma_{\mathrm{y}}(x)$ and $\sigma_{\mathrm{z}}(x)$ are functions of $x$ and are the standard deviations of the spore plume in the crosswind $(y)$ and vertical $(z)$ directions, respectively, and $U$ is the average wind speed in the downwind direction $(x)$. The factors $\sigma_{\mathrm{y}}$ and $\sigma_{\mathrm{z}}$ represent dilution of $C$ by turbulent mixing and wind shear in the atmosphere $(3,46)$. The two exponential factors account for the reduction in $C$ with distance away from the centerline of the plume. For purposes of illustration here, we limit our attention to points along the plume centerline at ground level, i.e., $y=z$ $=0$. Values of $C$ are maximum $\left(C_{\max }\right)$ along this line. $C_{\max }$ decreases with distance from a source as the spore plume expands into an ever-increasing volume of air, characterized by the product of $U, \sigma_{\mathrm{y}}$, and $\sigma_{z}$ in the denominator of equation 5 . The standard deviations $\sigma_{\mathrm{y}}$ and $\sigma_{\mathrm{z}}$ are functions of downwind distance and thermodynamic stability of the atmosphere $(5,46,51)$. The fraction $f(x)$ is affected by a combination of wet and dry deposition processes.

Atmospheric turbulence causes $C$ to decrease rapidly with increasing distance from a source and tends to diminish the importance of external sources of $V$. inaequalis ascospores compared with sources within an orchard. Rain plays a major role in the long-distance (several $\mathrm{km}$ ) transport of ascospores. It tends to reduce the effect of spore dilution in the vertical direction, because raindrops sweep through the entire column of air containing spores and bring them to the ground. After a transport distance of only a few hundred meters downwind, the spore plume will generally have spread enough vertically so that rainfall is the main mechanism for delivering spores to the ground or susceptible tissue. $D_{\mathrm{F}}(x)$ depends strongly on rainfall rate, $R$. Therefore, to calculate the deposition of ascospores, it is important to account for the rate of rainfall (or lack of rain) during the period of spore release.

For purposes of illustration, it is assumed that spore release rate, rainfall rate, and wind speed and direction remain constant during a spore release event. The model equations indicate that the relative risk of infection at a downwind distance of $8 \mathrm{~km}$ can differ by two orders of magnitude depending on whether $R$ during a transport event is 2 or $16 \mathrm{~mm} \mathrm{~h}^{-1}$ (Fig. 20). Risk of infection at downwind distances $>5 \mathrm{~km}$ is higher during light rains of 1 to $2 \mathrm{~mm} \mathrm{~h}^{-1}$ than for either lower or higher rainfall rates. Deposition during negligible rainfall $(R=0)$ is considerably smaller over the range of distances in the graph than for $R=$ 2,4 , or $8 \mathrm{~mm} \mathrm{~h}^{-1}$. In general, ascospores will be carried farther from a source when $R=0$, but few of them will reach the ground. Clearly, washout of ascospores by

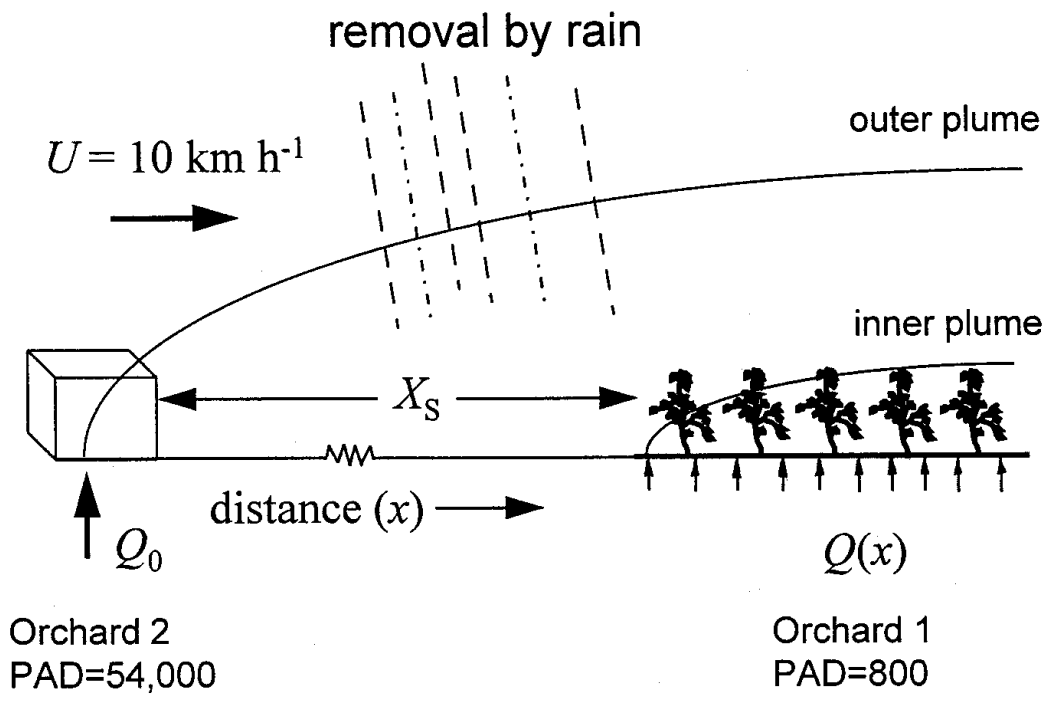

Fig. 21. Scenario for the calculated results presented in Figure 22. Ascospores are released simultaneously in a managed orchard (orchard 1, where 160 ascospores $\mathrm{m}^{-2}$ are released) and in a distant, off-farm, unmanaged orchard (orchard 2, where 10,800 ascospores $\mathrm{m}^{-2}$ are released). The inoculum source is assumed to be spatially uniform within the orchards. The trees are dwarf Mclntosh apple trees in the pink fruit bud stage. Wind speed is constant at $10 \mathrm{~km} \mathrm{~h}^{-1}$ and wind direction is constant and directly from orchard 2 to orchard 1 . The sawtooth break in the $x$-axis indicates that the distance between orchard 1 and orchard 2 was allowed to vary in the calculations. 
rain has important implications for scab control both on a farm and on a regional (county) scale. The model has not been validated on a regional scale and, at present, is to be used only as a rough guide. Some of the shortcomings that must be addressed are: the use of a theoretical washout coefficient that has not been validated experimentally and the probable lack of complete ascospore retention on leaves during rain. The assumption that $V$. inaequalis ascospores survive well for the length of time it takes for them to be transported 10 to $15 \mathrm{~km}$ by wind is probably valid $(18,39)$, especially as this usually occurs during overcast conditions. For calculating outcomes of a particular event, large uncertainties still remain in the number of spores released and in the probability of infection during changing weather.

Comparing risk of scab infections due to in-orchard and exogenous sources of inoculum. How many scab infections could be initiated in a managed orchard by "in-orchard" and external sources of inoculum? This first attempt to relate Potential Ascospore Dose (PAD) $(29,40)$ to the number of scab infections will be limited to a particular set of conditions (Fig. 21). Calculations are carried out for the aerial transport of ascospores simultaneously released within a managed orchard and within a distant unmanaged orchard several $\mathrm{km}$ upwind of the managed orchard. The curved lines in the figure schematically represent the spore plumes for spores originating from orchard 2 (upper curved line; outer plume) and from orchard 1 (lower curved line; inner plume). K-theory (equations 1 and 2) is used to calculate the number of lesions in orchard 1 that originate from inoculum released in that orchard. A Gaussian plume model (equations 4 and 5) is used to calculate the number of lesions in orchard 1 that originate from inoculum released from orchard 2. The calculations presented are for the number of lesions expected to develop in a managed orchard for a given release of ascospores in that orchard and in the external source. In this example, wind speed is held constant, but rainfall rate $R$ and distance $X_{\mathrm{S}}$ between the orchard and the outside source are allowed to vary.

The area of the managed orchard (orchard 1) and the off-farm, unmanaged orchard (orchard 2) are both 1 ha $(100 \times$ $100 \mathrm{~m}$ ). The trees are dwarf McIntosh in the pink fruit bud stage (22) of development $\left(I_{\mathrm{E}}=0.1\right.$; Fig. 5). The trees in the model orchards are planted at a spacing of $2.1 \mathrm{~m}$ within rows and $4.0 \mathrm{~m}$ between rows, yielding 1,190 trees ha ${ }^{-1}$. At the pink fruit bud development stage, the leaf and floral tissue area in the orchard is rather sparse. For our example, we assume that there are 420 buds per tree, or about 50 buds $\mathrm{m}^{-2}$ of ground area. To obtain the area of susceptible tissue, we combine this bud density with the results for the amount of susceptible area per bud presented in Figure 6; this yields an area of susceptible tissue per unit ground area equal to 0.16 . The PAD in orchard 1 is set equal to 800 , while the PAD in orchard 2 is equal to 54,000 . In both instances, it is assumed that $20 \%$ of the season's total inoculum is released (Fig. 4) during the event, so that 160 ascospores $\mathrm{m}^{-2}$ are released in orchard 1 and 10,800 ascospores $\mathrm{m}^{-2}$ are released in orchard 2 during the release event. Wind speed is constant at $10 \mathrm{~km} \mathrm{~h}^{-1}$, and wind direction is constant and directly from orchard 2 to orchard 1 . It is assumed that all deposited ascospores are retained (not washed off) and that conditions for infection are optimal $(40,52)$, so the results are expected to yield an upper estimate for disease incidence.

The results of these calculations are shown in Figure 22. The calculated disease incidences in orchard 1 that result from inoculum released in orchard 1 are indicated by black lines, while incidences in orchard 1 resulting from inoculum released in orchard 2 are shown by colored lines. The number of lesions due to the in-orchard source increases steadily with rainfall rate $R$ (upper black line). The lower black line and the gray shaded area are shown to remind us that the retention of deposited ascospores may be less than complete, especially for high values of $R$. Values of $R$ as high as $25 \mathrm{~mm} \mathrm{~h}^{-1}$ are very rare and are presented as a practical upper limit. At present, there is no experimental basis for drawing the lower black line.
Interestingly, the disease incidence in orchard 1 due to spores released by the distant source (orchard 2) first increases, reaches a peak, and then decreases with rainfall rate $R$ (colored lines). It is no surprise that a source $1.5 \mathrm{~km}$ distant (red line) would contribute more than sources farther away. It is interesting that more distant sources have a maximum impact for relatively low values of $R$ and reduced impact as $R$ increases above 2 to $3 \mathrm{~mm} \mathrm{~h}^{-1}$. The maximum disease incidence in orchard 1 resulting from the in-orchard source of inoculum occurs at the middle of its downwind edge (upper black line, Fig. 22). A calculated disease incidence of $2 \%$ corresponds to a lesion density of one lesion per $\mathrm{m}^{2}$ of orchard ground area, or one lesion per 50 buds in our example (see above).

The results of these calculations are very sensitive to wind speed ( $U$ was held fixed at $10 \mathrm{~km} \mathrm{~h}^{-1}$ for results shown in Fig. 22). As wind speed decreases, the relative impact of the in-orchard source increases while the impact of the distant source decreases dramatically. Ascospores released in the orchard during conditions of low wind speed spend more time in the orchard, and spore concentrations are higher there because they are not so quickly swept out by the wind. In contrast, ascospores that are transported from a distant orchard during lower wind speeds are exposed to rain longer, and more are washed out of the air. For a relatively low wind speed of 2 $\mathrm{km} \mathrm{h}^{-1}$, calculations (not shown) indicate

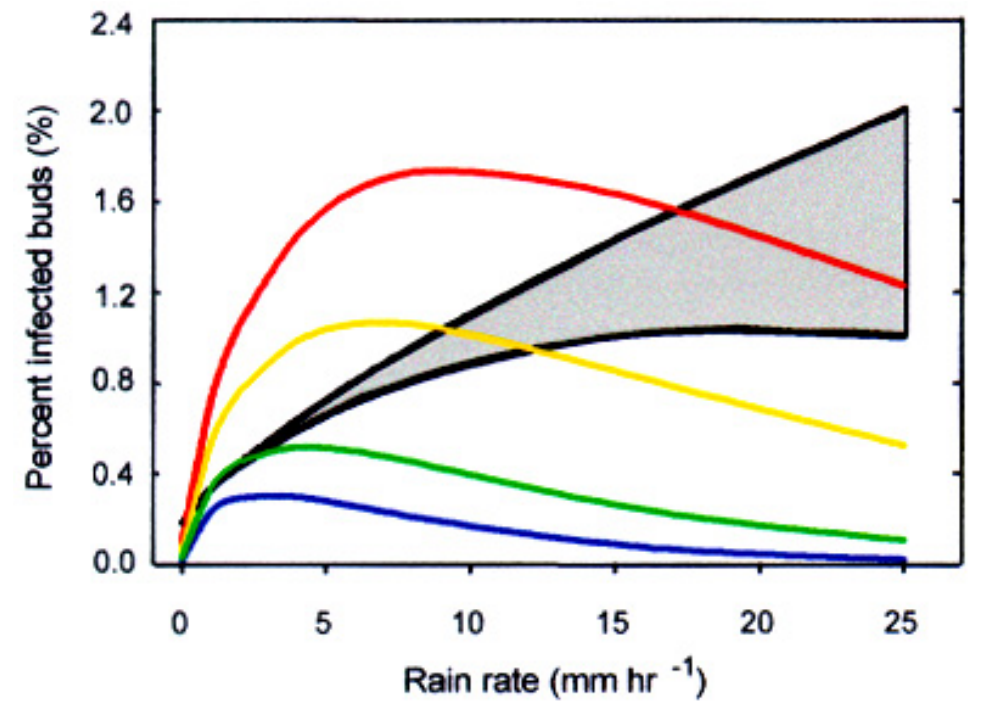

Fig. 22. Comparison of the estimated disease incidence in a $1 \mathrm{~m}^{2}$ area at the downwind edge of a 1-ha orchard due to (i) an in-orchard source, calculated using equations 1 and 2, and (ii) a distant source, calculated using equations 4 and 5 . The incidence due to the in-orchard source is calculated to increase steadily with $R$ (black lines), while the contribution due to a distant source first increases and then decreases with $R$ and is a strong function of orchard separation distance $X_{\mathrm{S}}$. The curves representing disease incidence due to ascospores released at separation distances $X_{S}=1.5,2,3$, and $4 \mathrm{~km}$ are represented by the red, yellow, green, and blue lines, respectively. The lower black line and the gray shaded area indicate that the retention of deposited ascospores may not be $100 \%$, especially for high values of $R$. For this example, $2 \%$ disease incidence on a per-bud basis corresponds to one lesion per $\mathrm{m}^{2}$ of orchard floor area. 
that a source at a distance of $1.5 \mathrm{~km}$ can make a significant contribution to infections in the orchard for values of $R<2 \mathrm{~mm}$ $\mathrm{h}^{-1}$, but it makes relatively little contribution for greater values of $R$. Sources more distant than $3 \mathrm{~km}$ make almost no contribution compared with in-orchard inoculum for this low wind speed.

\section{Summary and Concluding Remarks}

Strategies for controlling apple scab with reduced use of chemical pesticides require improved methods for predicting potential disease spread in terms of the amount of inoculum in a source area. Our success hinges on an ability to determine when levels of inoculum are sufficiently low to forego, or to postpone, chemical control. The maturation and release of ascospores and the development of susceptible host tissue are dynamic processes, so that risk of infection changes dramatically during the season. Assuming favorable interactions among the host, the pathogen, and the weather, spore dispersal models can be used to quantify probabilities of infection in terms of the amount of available inoculum.

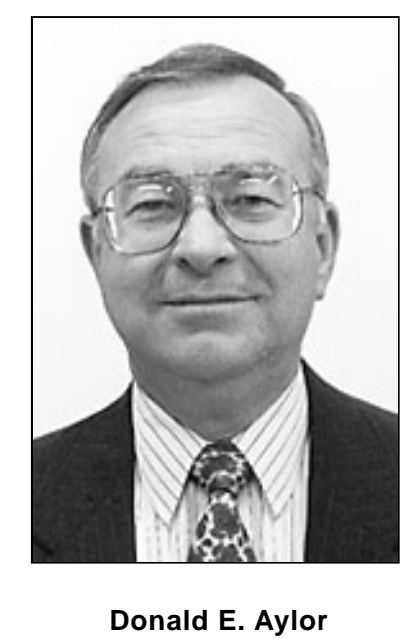

Dr. Aylor is a research scientist and head of the Department of Plant Pathology and Ecology at The Connecticut Agricultural Experiment Station. He received his B.S., M.S., and Ph.D. degrees in mechanical engineering at the State University of New York at Stony Brook. He joined the Connecticut station as an assistant scientist in 1969, where he has conducted numerous studies on biophysical aspects of spore dispersal and disease spread. Dr. Aylor's current research is centered on quantifying aerial dispersal of Venturia inaequalis ascospores to calculate probabilities of primary scab infection and improve disease management decisions.
The probability of apple scab infection increases as the number of ascospores in the air around developing apple tissue increases. Atmospheric turbulence and washout by rain cause aerial ascospore concentrations to decrease rapidly with increasing distance from a source. Thus, external sources of $V$. inaequalis ascospores can be relatively unimportant compared with sources within an orchard, but this depends greatly on the size and proximity of the external source of spores, the wind speed, and the rainfall rate. The model indicates that an abandoned 1-ha orchard with high levels of scab from the previous season, up to 2 to $5 \mathrm{~km}$ distant, could cause infections in a managed orchard. The model can help us evaluate sources of attrition of airborne ascospore inoculum in the field and, thus, improve the correspondence between laboratory and field methods. Attrition can be due to ascospore removal from air by rain, mechanical and biological breakdown of the inoculumharboring leaf litter, and entrapment of released ascospores in ground cover.

The aerobiological model is still under development and requires more testing and calibration to be quantitative. Spore dispersal models can help us make rational decisions about fungicide use, timing of sprays, sanitation, and usefulness of scouting, quarantine, and eradication strategies. We can use them to assess the relative risk of infection from primary inoculum in an orchard compared with inoculum in a distant less well managed, or abandoned, orchard. The model can help determine those situations where there is a possibility of shortening the primary scab control season, or indicate where caution may be warranted. It remains as a major goal to develop the model to a level where it can help growers evaluate the extent to which scouting, sanitation measures, and ground cover management might reduce the need for fungicides in disease management and provide them with more and better options for control. In this article, I have tried to indicate where we currently stand in this endeavor, where progress can and should be made, and where there are still significant barriers (both biological and physical) to greater quantification. It is my hope that some readers will be inspired to contribute to this effort.

\section{Acknowledgments}

I thank S. L. Anagnostakis, S. M. Douglas, F. J. Ferrandino, and two anonymous reviewers for helpful comments on the manuscript, and P. W. Thiel for excellent technical assistance and for drafting some of the figures. This material is based upon work supported in part by Hatch Funds and by the Cooperative State Research, Education, and Extension Service, U.S. Department of Agriculture, under Agreement No. 97-34103-4125.

\section{Literature Cited}

1. Agrios, G. N. 1988. Plant Pathology. 3rd ed. Academic Press, San Diego, CA.

2. Anagnostakis, S. L., and Aylor, D. E. 1991.
Efficiency of ascospores of Venturia inaequalis in producing scab lesions on apple leaves. Plant Dis. 75:918-920.

3. Arya, S. P. 1988. Introduction to Micrometeorology. Academic Press, San Diego, CA.

4. Aylor, D. E. 1978. Dispersal in time and space: Aerial pathogens. Pages 159-180 in: Plant Disease: An Advanced Treatise. II. J. G. Horsfall and E. B. Cowling, eds. Academic Press, New York.

5. Aylor, D. E. 1986. A framework for examining inter-regional aerial transport of fungal spores. Agric. For. Meteorol. 38:263-288.

6. Aylor, D. E. 1989. Aerial spore dispersal close to a focus of disease. Agric. For. Meteorol. 47:109-122.

7. Aylor, D. E. 1990. The role of intermittent wind in the dispersal of fungal pathogens. Annu. Rev. Phytopathol. 28:73-92.

8. Aylor, D. E. 1993. Relative collection efficiency of Rotorod and Burkard spore samplers for airborne Venturia inaequalis ascospores. Phytopathology 83:1116-1119.

9. Aylor, D. E. 1994. Role of turbulence in escape of Venturia inaequalis ascospores from a grass canopy. Pages 397-400 in: Proc. Conf. Biometeorol. Aerobiol., 11th. Am. Meteorol. Soc., Boston, MA.

10. Aylor, D. E. 1995. Vertical variation of aerial concentration of Venturia inaequalis ascospores in an apple orchard. Phytopathology 85:175-181.

11. Aylor, D. E. 1996. Comparison of the seasonal pattern of airborne Venturia inaequalis ascospores with the release potential of $\mathrm{V}$. inaequalis ascospores from a source. Phytopathology 86:769-776.

12. Aylor, D. E. 1996. Quantifying the probability of apple scab fungus infection to improve disease management. Frontiers Plant Sci. 49(1):5-8.

13. Aylor, D. E., and Anagnostakis, S. L. 1991. Active discharge distance of ascospores of Venturia inaequalis. Phytopathology 81:548551.

14. Aylor, D. E., and Ducharme, K. M. 1995. Wind fluctuations near the ground during rain. Agric. For. Meteorol. 76:59-73.

15. Aylor, D. E., and Ferrandino, F. J. 1989. Dispersion of spores released from an elevated line source within a wheat canopy. BoundaryLayer Meteorol. 46:251-273.

16. Aylor, D. E., and Kiyomoto, R. K. 1993. Relationship between aerial concentration of Venturia inaequalis ascospores and development of apple scab. Agric. For. Meteorol. 63:133-147.

17. Aylor, D. E., and Qiu, J. 1996. Micrometeorological determination of release rate of Venturia inaequalis ascospores from a groundlevel source during rain. Agric. For. Meteorol. 81:157-178.

18. Aylor, D. E., and Sanogo, S. 1997. Germinability of Venturia inaequalis conidia exposed to sunlight. Phytopathology 87:628-633.

19. Aylor, D. E., and Sutton, T. B. 1992. Release of Venturia inaequalis ascospores during unsteady rain: Relationship to spore transport and deposition. Phytopathology 82:532-540.

20. Aylor, D. E., Wang, Y. S., and Miller, D. R. 1993. Intermittent wind close to the ground within a grass canopy. Boundary-Layer Meteorol. 66:427-448.

21. Buller, A. H. R. 1909. Researches on Fungi. Vol. 1. Longmans, Green and Co., London.

22. Childers, N. F. 1983. Modern Fruit Science. Horticultural Publications, Gainesville, FL.

23. Csanady, G. T. 1973. Turbulent Diffusion in the Environment. Reidel Publ. Co., Dordrecht, Holland.

24. Denmead, O. T., Simpson, J. R., and Freney, J. R. 1977. A direct field measurement of ammonia emission after injection of anhy- 
drous ammonia. Soil Sci. Am. J. 41:10011004.

25. Falk, S. P., Gadoury, D. M., and Seem, R. C. 1995. Analysis of risk of primary apple scab infection. (Abstr.) Phytopathology 85:1556.

26. Flesch, T. K., and Wilson, J. D. 1992. A twodimensional trajectory-simulation model for non-Gaussian inhomogeneous turbulence within plant canopies. Boundary-Layer Meteorol. 61:349-374.

27. Gadoury, D. M., and MacHardy, W. E. 1982. Preparation and interpretation of squash mounts of pseudothecia of Venturia inaequalis. Phytopathology 72:92-95.

28. Gadoury, D. M., and MacHardy, W. E. 1982. A model to estimate the maturity of ascospores of Venturia inaequalis. Phytopathology 72:901-904.

29. Gadoury, D. M., and MacHardy, W. E. 1986. Forecasting ascospore dose of Venturia inaequalis in commercial apple orchards. Phytopathology 76:112-118.

30. Gadoury, D. M., MacHardy, W. E., and Rosenberger, D. A. 1989. Integration of pesticide application schedules for disease and insect control in apple orchards of the Northeastern United States. Plant Dis. 73:98-105.

31. Gadoury, D. M., Seem, R. C., Rosenberger, D. A., Wilcox, W. F., MacHardy, W. E., and Berkett, L. P. 1992. Disparity between morphological maturity of ascospores and physiological maturity of asci in Venturia inaequalis. Plant Dis. 76:277-282.

32. Gadoury, D. M., Seem, R. C., and Stensvand, A. 1996. Ascospore discharge in Venturia inaequalis. Norw. J. Agric. Sci., Suppl. 17:205-219.

33. Gadoury, D. M., Stensvand, A., and Seem, R. C. 1996. A wind tunnel for controlled-environment studies of ascospore release by Venturia inaequalis. Phytopathology 86:596-601.

34. Gregory, P. H. 1973. The Microbiology of the Atmosphere. John Wiley \& Sons, New York

35. Hirst, J. M., and Stedman, O. J. 1962. The epidemiology of apple scab (Venturia inae- qualis (Cke.) Wint.). II. Observations of the liberation of ascospores. Ann. Appl. Biol. 50:525-550.

36. Hirst, J. M., and Stedman, O. J. 1962. The epidemiology of apple scab (Venturia inaequalis (Cke.) Wint.). III. The supply of ascospores. Ann. Appl. Biol. 50:551-567.

37. James, J. R., and Sutton, T. B. 1982. Environmental factors influencing pseudothecial development and ascospore maturation of Venturia inaequalis. Phytopathology 72:10731080 .

38. Jones, A. L., and Aldwinckle, H. S., eds. 1990. Compendium of Apple and Pear Diseases. American Phytopathological Society, St. Paul, MN

39. Keitt, G. W., and Jones, L. K. 1926. Studies of the epidemiology and control of apple scab. Wis. Agric. Exp. Stn. Res. Bull. No. 73

40. MacHardy, W. E. 1996. Apple Scab: Biology, Epidemiology, and Management. American Phytopathological Society, St. Paul, MN.

41. MacHardy, W. E., and Gadoury, D. M. 1985. Forecasting the seasonal maturation of ascospores of Venturia inaequalis. Phytopathology 75:381-385.

42. MacHardy, W. E., and Gadoury, D. M. 1986. Patterns of ascospore discharge by Venturia inaequalis. Phytopathology 76:985-990.

43. MacHardy, W. E., Gadoury, D. M., and Rosenberger, D. A. 1993. Delaying the onset of fungicide programs for control of apple scab in orchards with low potential ascospore dose of Venturia inaequalis. Plant Dis. 77:372-375.

44. MacHardy, W. E., and Jeger, M. J. 1983. Integrating control measures for the management of primary apple scab Venturia inaequalis (Cke.) Wint. Prot. Ecol. 5:103-125.

45. Mills, W. D. 1944. Efficient use of sulfur dusts and sprays during rain to control apple scab. Cornell Ext. Bull. 630.

46. Pasquill, F. 1974. Atmospheric Diffusion. John Wiley \& Sons, New York.

47. Sanogo, S., and Aylor, D. E. 1997. Infection efficiency of Venturia inaequalis ascospores as affected by apple flower bud developmental stage. Plant Dis. 81:661-663.

48. Schrodter, H. 1960. Dispersal by air and water - the flight and landing. Pages 169-227 in Plant Pathology: An Advanced Treatise. Vol. 3. J. G. Horsfall and A. E. Dimond, eds. Academic Press, New York

49. Schwabe, W. F. S. 1979. Changes in the susceptibility of apple leaves as influenced by age. Phytophylactica 11:53-56.

50. Schwabe, W. F. S., Jones, A. L., and Jonker, J. P. 1984. Changes in the susceptibility of developing apple fruit to Venturia inaequalis. Phytopathology 74:118-121.

51. Slade, D. H., ed. 1968. Meteorology and Atomic Energy, U.S. Atomic Comm., Oak Ridge, TN. pp. 121, 134.

52. Stensvand, A., Gadoury, D. M., Amundsen, T. Semb, L., and Seem, R. C. 1997. Ascospore release and infection of apple leaves by conidia and ascospores of Venturia inaequalis at low temperatures. Phytopathology 87:1046-1053.

53. Sutton, T. B. 1996. Changing options for the control of deciduous fruit tree diseases. Annu. Rev. Phytopathol. 34:527-547.

54. Szkolnik, M. 1969. Maturation and discharge of ascospores of Venturia inaequalis. Plant Dis. Rep. 53:534-537.

55. Thomson, D. J. 1987. Criteria for the selection of stochastic models of particle trajectories in turbulent flows. J. Fluid Mech. 180:529-556

56. Wilson, J. D., Catchpoole, V. R., Denmead, O. T., and Thurtell, G. W. 1983. Verification of a simple micrometeorological method for estimating ammonia loss after fertiliser application. Agric. Meteorol. 29:183-189.

57. Wilson, J. D., Legg, B. J., and Thomson, D. J. 1983. Calculation of particle trajectories in the presence of a gradient in turbulent-velocity variance. Boundary-Layer Meteorol. 27:163169. 